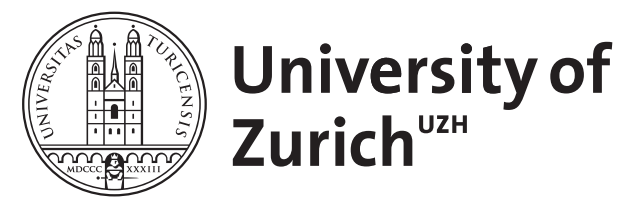

\title{
Electrosurgery in urology: recent advances
}

Tremp, M ; Hefermehl, L ; Largo, R ; Knönagel, H ; Sulser, T ; Eberli, D

\begin{abstract}
Inadequate hemostasis is one of the most important causes of morbidity and mortality following urological surgery. Despite the long-term usage of coagulation, there is an ongoing development of new devices, including bipolar transurethral resection of the prostate or new vessel-sealing devices. A thorough understanding of the advantages and disadvantages of these new instruments can improve the operative experience for both the urologist and patient. The optimal coagulation system should be small, efficient, easy to handle and with low heat spread. In this article, we analyze different electrothermal coagulation systems and modern tissue-sealing devices in urological applications with the aim to substantiate the advantages and disadvantages of each technique in terms of efficacy and safety.
\end{abstract}

DOI: https://doi.org/10.1586/erd.11.26

Posted at the Zurich Open Repository and Archive, University of Zurich ZORA URL: https://doi.org/10.5167/uzh-51105

Journal Article

Accepted Version

Originally published at:

Tremp, M; Hefermehl, L; Largo, R; Knönagel, H; Sulser, T; Eberli, D (2011). Electrosurgery in urology: recent advances. Expert Review of Medical Devices, 8(5):597-605.

DOI: https://doi.org/10.1586/erd.11.26 


\section{Electrosurgery in Urology: Recent Advances}

Mathias Tremp, MD, Lukas Hefermehl, MD, Remo Largo, MD, Hartmut Knönagel, MD, Tullio

Sulser, MD, Daniel Eberli, MD, PhD

\section{Keywords:}

Review, Monopolar, Electrothermal bipolar coagulator, Electrosurgery, Safety, Feasibility studies

\section{Corresponding Author:}

Daniel Eberli MD PhD

Department of Urology

University Hospital Zurich

Frauenklinikstr. 10

$\mathrm{CH}-8091$ Zurich

Schweiz / Switzerland

daniel.eberli@usz.ch

Tel: + 41442559630

$\mathrm{Fax}+41442559620$ 


\section{Body of article}

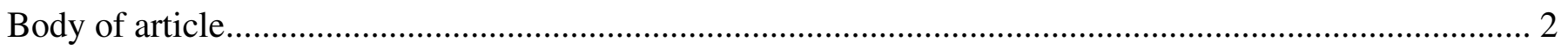

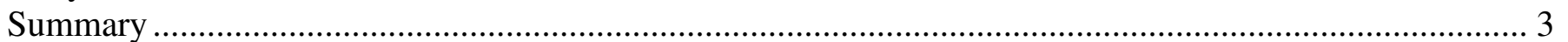

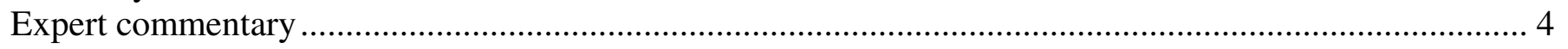

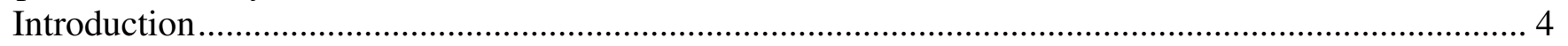

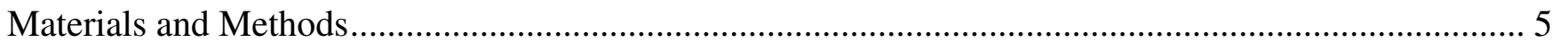

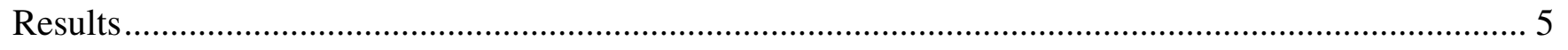

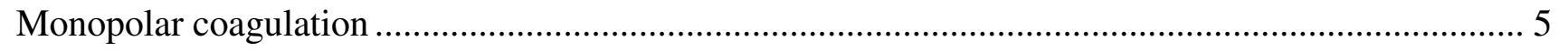

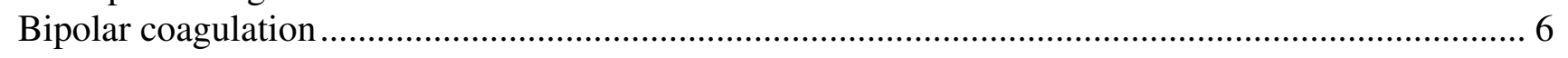

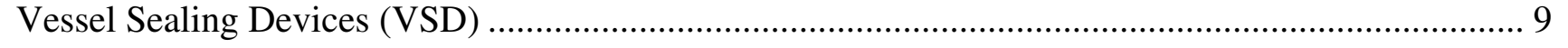

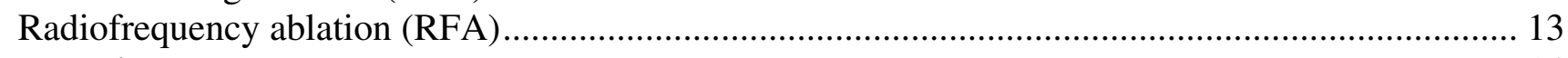

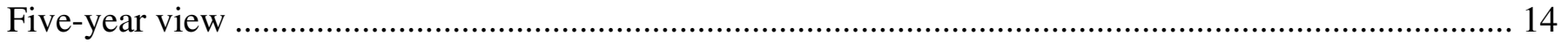

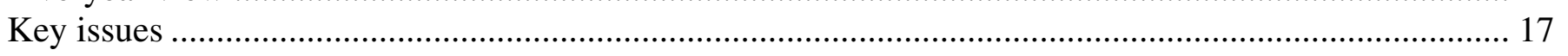

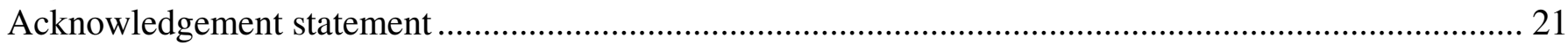

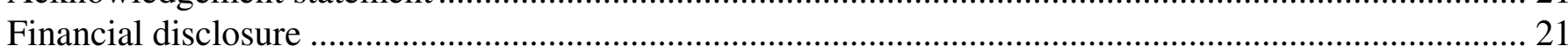




\section{Summary}

Inadequate haemostasis is one of the most important causes of morbidity and mortality following urological surgery. Despite the long term usage of coagulation, there is an ongoing development of new devices including, bipolar transurethral resection of the prostate (B-TURP) or new vessel sealing devices (VSD). A thorough understanding of the advantages and disadvantages of these new instruments can improve the operative experience for both urologist and patient. The optimal coagulation system should be small, efficient, easy to handle and with low heat spread. In this review we analysed different electrothermal coagulation systems and modern tissue sealing devices in urological applications with the aim to substantiate the advantages and disadvantages of each technique in terms of efficacy and safety. 


\section{Expert commentary}

\section{Introduction}

Electrosurgery uses high-frequency electrosurgical energy, modified from standard electricity by an electrosurgical generator, to create a desired clinical effect.[1-2] A standard $60 \mathrm{~Hz}$ alternating electric current is unsafe for use in the body as it subjects the patient to the risk of neuromuscular stimulation and electrocution.[2] An electrosurgical generator is used to increase the frequency over $100^{\prime} 000 \mathrm{~Hz}$ to eliminate nerve and muscle stimulation and to render the energy safe.[2] Tissue effects that can be achieved with electrosurgery can be roughly divided into three basic groups: cutting, fulguration, and desiccation. Achieving these effects depend on the following factors: current density, time, electrode size, tissue conductivity, and type of current waveform.[1]

Electrosurgical generators can apply energy in either a monopolar or bipolar fashion. Monopolar coagulation is the oldest method in which current is applied through a handheld active electrode and travels back to the generator through an inactive electrode attached to the patient (the grounding pad), so that the patient is part of the electrical circuit. In monopolar TURP, the target tissue is the prostate, where the majority of the energy gets transmitted and converted to heat, achieving the desired tissue effect or cutting and/or coagulation.[2] The tissue effect is determined by power setting (wattage), contact surface area of the wire loop, the type of radio frequency (RF) energy, duration of tissue contact, and tissue resistance (impedance).[2] Common to all electrocoagulative devices is a rise in tissue temperature during application of energy. In general, below $45^{\circ} \mathrm{C}$, thermal damage to tissue is reversible. As tissue temperatures exceed $45^{\circ}$, the proteins in the tissue become denatured, losing their structural integrity. Above $90^{\circ} \mathrm{C}$, the liquid in the tissue evaporates, resulting in desiccation if the tissue is heated slowly or vaporization if the heat is delivered rapidly.[1] Once the tissue temperatures reach $200^{\circ} \mathrm{C}$, the remaining solid components of the tissue are reduced to carbon.

Despite the ongoing development of new devices like bipolar transurethral resection of the prostate (B-TURP), vaporisation of the prostate or new vessel sealing devices (VSD), potential pitfalls or complications also exist. A thorough understanding of the advantages and limitations 
of these novel instruments can improve the operative experience for both urologist and patient. The optimal coagulation system should be small, efficient, easy surgical handling with a high burst pressure and low heat spread. Since many of these attributes are exclusive of each other, different application will require different instruments and settings.

In this review we analysed different electrothermal coagulation devices and modern tissue sealing systems in urological applications with the aim to substantiate the advantages and disadvantages of each technique in terms of efficacy and safety.

\section{Materials and Methods}

\section{Literature search strategy}

A literature review was performed from 1989 to 2010 using the US National Institutes of Health's PubMed database. The reference lists of all selected papers were further reviewed for potentially relevant studies. Eligible studies were full papers written in English language reporting on at least one of the two primary outcomes of interest: efficacy and safety.

\section{Article selection}

Combinations of the following key words were used: monopolar, bipolar, vessel sealing devices, blood loss, operative time, prostatectomy, cystectomy, kidney surgery and urology. There were six randomized controlled trials[3-8] and one systematic review to evaluate the evidence based on randomized controlled trials (RCTs).[9] Six review articles were studied as full-text version.[12,10-13] In addition, five comparative studies, ten animal studies and several case series with a total of more than $10^{\prime} 000$ patients were analysed. Table $1 \& 2$ gives an overview of the electrothermal sealing systems in urological applications.

\section{Results}

\section{Monopolar coagulation}

Monopolar electrocoagulation has proven to be less effective and safe.[14] This is because the physical characteristics of single radiofrequency (RF) energy with limited tissue effect.[15] Electrosurgical delivery of energy using monopolar instruments can be enhanced by 
incorporating a stream of argon gas to improve the surgical effectiveness in maintaining hemostasis over larger surfaces.[1] The ultimate dual function (cutting and coagulation) rests in having two independent RF energies capable of exerting the desired hemostatic tissue effect.[15] For procedures performed in a liquid medium such as TURP, the liquid medium needs to be nonconductive in order to prevent energy dispersing away from the target organ. Lowelectrolyte hypo-osmolar irrigation fluids such as glycine solutions are used in monopolar TURP. However, such solutions subject the patient to the risk of dilutional hyponatremia and TUR syndrome.[2]

\section{Bipolar coagulation}

Bipolar delivery of energy does not require a dispersive return electrode pad because both the active electrode and the return electrode are integrated into the energy delivery forceps with the target tissue between. Bipolar electrosurgical instruments have evolved from being used in the coagulation of tissue to the creation of complete fusion of the intimal layers of vascular structures. Further, bipolar energy is also used to improve the simultaneous cutting and coagulation during surgeries of highly vascularised tissues. The main advances over the last year were made in the use of biopolar devices for endourology and the application of biopolar energy to Vessel Sealing Devices (VSD).

One randomized controlled trial assessed the efficacy and safety of the monopolar transurethral resection of the prostate (TURP) and compared it with the bipolar electrocautery and physiologic saline.[4] In their study, the authors found no difference in resection time, haemoglobin fall or resected tissue. However, there was a significant lower serum $\mathrm{Na}$ of $-4.6 \mathrm{mEq} / \mathrm{L}$ in the monopolar electrocautery group when compared to bipolar electrocautery $(-1.2 \mathrm{mEq} / \mathrm{L}, \mathrm{p}<0.001)$.

Mandhani and coworkers monitored the temperature with a needle electrode in 15 cases of athermal nerve sparing and 10 cases of non-nerve sparing robotic radical prostatectomy (RRP).[16] In this study, the mean time to return to baseline temperature was 3 seconds more with bipolar than monopolar and the authors concluded that bipolar cautery may not be safer than monopolar because of a greater rise in temperature of surround tissue within $1 \mathrm{~cm}$ of its use.[16] Clearly, monopolar devices continue to play a defined role in modern surgery. 


\section{Endourology}

The introduction of bipolar technology in TURP seems to be a promising technical modification offering possible benefits both for the patient[17] and for training purposes.[18] It shares similar clinical efficacy with monopolar transurethral resection of the prostate, durable in time with low long-term complications rates. It has minimized bleeding risks and eliminated transurethral resection syndrome by using normal saline as irrigation fluid. In bipolar TURP, the two poles (active and return) are incorporated into the electrode design.[2] Mamoulakis et al. evaluated the evidence based on 16 randomized controlled trials (RCTs) that compare bipolar-TURP with monopolar transurethral resection of the prostate (M-TURP) in patients with benign prostatic obstruction (BPO) and conducted a quantitative meta-analysis in an attempt to provide conclusions based on level 1a evidence.[9] Considering the two main limitations, low trial quality and the relatively limited follow-up, this systematic review provides the strongest available evidence to date showing that no clinically relevant differences in short-term efficacy exist between the two techniques. Furthermore, no differences were evident regarding operation time and rates of adverse events such as transfusions and retention after catheter removal

Since january 2008, TURis plasma vaporisation offers a minimally invasive alternative. Due to the TURis plasma vaporisation electrode development, and its addition to the current selection of TURis electrodes (large loop, band electrode and TUEB (Transurethral Enucleation Bipolar) electrode for enucleation), the method combines the advantages of vaporisation with the benefits of bipolar resection. The electrical current mainly flows directly from the electrode loop to the electrode tube as the electrical impedance of the surrounding saline solution is significantly lower compared to the human tissue $(1: 10)$. Thus the current flow is locally limited and, compared to the monopolar technique, the leakage current is reduced by $70 \%$.

In a randomized controlled trial, Fragerström et al. randomized 202 consecutive patients to undergo TURP using either a bipolar system or a monopolar system. The authors could show that bipolar TURP using the TURis system was performed with the same speed as monopolar TURP but causes 34\% less bleeding. Bipolar TURP also required fewer erythrocyte transfusions than the conventional monopolar technique.[6] Puppo et al. evaluated the safety and outcome of TURis in 1000 cases with a median follow-up of 12 months.[19] None of the patients 
experienced a TUR syndrome while the TURis device after a median resection time of 42 minutes was not associated with a greater incidence of urethral strictures (2.7\%) compared to data obtained with monopolar devices. The authors observed that in the TURis case there is a dispersion flow in optimal conditions of about 6-7mA and in abnormal conditions (multiuse) of about $50 \mathrm{~mA}$, and hence 20/25 times below the limit in normal conditions and 3 times below in abnormal conditions (reusing the same loop). Accordingly, they decided to use a new loop for each resection.[19] Ho and coworkers presented their preliminary results on clinical efficacy and safety with the TURis system in 45 patients with clinically significant BPH. Their study indicated that TURis is a safe and efficacious treatment for BPH at 1 year.[20] The same authors confirmed their results later in a prospective randomized study with a larger cohort of 100 patients. Mean resection time and mean weight of resected prostate tissue were comparable for both groups. Declines in the mean postoperative serum $\mathrm{Na}^{+}$for TURis and monopolar TURP groups were 3.2 and $10.7 \mathrm{mmol} / \mathrm{l}$, respectively $(p<0.01)$. However, there was no statistical difference in the decline in postoperative $\mathrm{Hb}$ between the two groups. Urethral strictures were observed in three cases of TURis and one patient in the monopolar group. The IPSS (International Prostate Symptom Score) and Qmax. improvements were comparable between the two groups at 12 months follow-up.[5]

The evidence derived from randomized clinical trials does not show a statistically significant difference of urethral strictures when bipolar energy is compared with monopolar.[11] This has been confirmed in a clinical review of bipolar TURP.[2] Similar efficacy between bipolar TURP and monopolar TURP has been shown with a significant lower adverse events with bipolar TURP. The rates of erectile and ejaculatory dysfunctions were similar with both systems at approximately $14 \%$ and $50 \%$, respectively.[2] In another study, Ko and coworkers compared the thermal and histopathological effects of two commercially available bipolar systems ((Gyrus PlasmaKinetic and Vista, both from Gyrus-ACMI Corporation, Maple Grove, MN, USA) and conventional monopolar transurethral resection (Force TM2, Valleylab, Boulder, CO, USA) of the prostate (TURP) in a canine model. In their study, bipolar TURP generated significantly less heat and histopathological evidence of thermal damage compared with monopolar TURP.[21] 


\section{Vessel Sealing Devices (VSD)}

With recent improvements in computing technology being integrated into electrosurgical generators, the use of sophisticated closed-loop feedback control algorithms has created the ability to fuse vascular structures up to $7 \mathrm{~mm}$ in diameter. This allows the surgeon to create an "autologous clip" to achieve hemostasis without suture, staples, or traditional clips. These "vessel sealing" devices were first introduced in 1998.

LigaSure is a bipolar electrosurgical device designed to deliver high current and very low voltage to tissue. It monitors tissue impedance between the jaws of the instrument and continuously adjusts the delivery of energy. It seals vessels by applying high, uniform mechanical compression while monitoring and adjusting energy delivery to the tissue. Because this product relies heavily on the collagen and elastin content of vessels to achieve hemostasis, it works well for arteries and veins but inconsistently in tissues where the blood supply is delivered predominantly by capillaries, which have a low collagen content.[22] Three articles reported a significantly reduced blood loss and operative time using the LigaSure device.[3,23-24] However, a potential drawback of vessel sealing devices are costs and the possibility of tissue injury leading to necrosis and perforation.[25-26] In a prospective randomized trial comparing thermal and mechanical endoscopic methods to obtain hemostasis, hemoclips has found to be superior to heat probe in preventing early recurrent bleeding ulcers.[8]

EnSeal $(\circledast)$ (Ethicon, Cincinnati, $\mathrm{OH}$ ) has been demonstrated to limit collateral thermal tissue damage to $<1.0 \mathrm{~mm}$. It has been shown that EnSeal works effectively and adjacent thermal tissue damage is significantly minimized when submerged in cold saline irrigation during hemostasis of the prostatic vascular pedicles (PVP).[27]

The Gyrus Plasma Trissector (GPT), (Gyrus Group PLC, Gyrus International, Ltd.UK) uses highpowered pulsed bipolar energy to produce a plasmakinetic field around the working elements and is designed to operate at temperatures that allow effective tissue dissection but result in minimal collateral damage and adherence to tissue.[28] 


\section{Open surgery}

Daskalopoulos et al. evaluated the use of an electrothermal bipolar coagulator (LigaSure device) in major urologic procedures, including open radical prostatectomies and radical cystectomies.[23] 58 patients aged 56-74 years (mean: 65 years) underwent open radical prostatectomy and open radical cystectomy performed by the same surgeon, employing either conventional ligation in the control group (radical prostatectomy, $n=15$; radical cystectomy $n=$ 9) or the LigaSure device in the study group (radical prostatectomy, $n=24$; radical cystectomy $n$ $=10)$ to ensure blood vessel patency. Effectiveness and postoperative outcomes were evaluated. The mean operation time was significantly shorter in the LigaSure group compared to the control group for both the prostatectomy (125 minutes vs. 144 minutes, $p<0.001)$ and the cystectomy procedures (253 minutes vs. 281 minutes, $p<0.001)$. In addition, the mean intraoperative blood loss was significantly lower in the LigaSure group compared to the control group for both prostatectomy $(569 \mathrm{ml}$ vs. $685 \mathrm{ml}, p=0.04)$ and cystectomy procedures $(637 \mathrm{ml}$ vs. $744 \mathrm{ml}, p=0.02$ ). There were no serious intraoperative or postoperative complications related to the use of the device.

Futher, Sengupta et al. evaluated the application of LigaSure in open urological surgery.[24] The VSD device was used in 32 consecutive open surgical cases, including 25 radical prostatectomies, five radical nephrectomies, one partial nephrectomy and one nephroureterectomy. The LigaSure device was used in pelvic lymphatics and prostatic, adrenal, gonadal and aberrant obturator vessels, as well as vessels associated with the ureter, vasa, seminal vesicles, peri-renal fat, peritoneum and peri-adrenal tissue. No additional clips or sutures were required to secure any vessels $<7 \mathrm{~mm}$ in diameter. The authors reported a significant reduction in intraoperative blood loss and operation time with LigaSure in open radical prostatectomy.[24] Postoperatively, there were no instances of haemorrhage, lymph leakage or lymphocele formation. The authors concluded that the VSD is safe and easy to use in major urological procedures. They also reported that some structures (e.g. the vas and the seminal vesicle) are difficult to control using clips because of their friability and poor access. The LigaSure device allowed them to seal these structures with much greater ease. Given the limited lateral thermal damage, they successfully used the device next to the iliac veins and the inferior 
vena cava. The device performed well even in the presence of blood or urine, as distinct from conventional diathermy.

Kennedy et al. used the LigaSure device on the spermatic cord structures and vas while performing an unilateral inguinal orchiectomy.[29] Once the spermatic cord was identified and dissected free from the vas, it was divided. The spermatic cord and the vas were successfully ligated using the LigaSure Max handset.[29] There are also reports of laparoscopic varicocele ligation with the LigaSure in male children and adolescents.[30] In a well-designed open study, Hruby and coworkers assessed the vessel sealing capabilities and the peripheral energy spread associated with currently available energy based surgical instruments.[31] They found a high burst pressure with the LigaSure (LS) and a rapid sealing time. The LS device was compared to two ultrasonic devices and a prototype plasmakinetic trissector and was found to be the overall best device. The best sealing was seen with the LS device and the poorest with the Harmonic Scalpel.[31]

The reusable $\mathrm{BiClamp}{ }^{\circledR}$ bipolar coagulation forceps has been available for open surgery procedures since 2002. Richter and coworkers studied the efficacy of the reusable BiClamp® versus the standard disposable LigaSure bipolar vessel sealing device using a porcine model.[32] In their study, the burst pressures of the BiClamp®-sealed arteries (842 $\pm 117 \mathrm{mmHg})$ did not differ from that of arteries sealed with LigaSure $(856 \pm 102 \mathrm{mmHg})$, but were significantly higher than the burst pressures of veins $(155 \pm 26$ and $216 \pm 71 \mathrm{mmHg}$, respectively) $(p<0.05)$. Independent of the sealing device used, thermal spread was found increased in veins compared to arteries. The authors concluded that the BiClamp® device is as appropriate as the LigaSure instrument to successfully ligate $2-7 \mathrm{~mm}$ arteries and veins, demonstrating supraphysiological bursting strengths and adequate luminal fusion healing. However, the BiClamp $\AA$ required an extra 2 to 3 seconds to seal arteries and veins. Thermal spread was increased along veins compared to arteries. However, the precise distance of spread was not reported.

\section{Laparoscopy}

Leonardo et al. compared the effectiveness of the LigaSure Atlas system with earlier methods in 30 patients affected by clinically localized renal-cell carcinoma who underwent transperitoneal 
laparoscopic radical nephrectomy with a three-trocar technique. They found no conversion in either group. Statistically significant differences were observed between conventional and LigaSure nephrectomy regarding mean intraoperative blood loss (485 v 100ml, respectively; $p<$ $0.005)$ and mean operative time (164 $\vee 68$ minutes, respectively; $p<0.05)$. No statistical difference was observed in the postoperative discharge time[3] and no evidence of collateral tissue injury or injuries to the intestinal tract were found.

Metzelder and coworkers evaluated the feasibility of LigaSure in laparoscopic transperitoneal heminephroureterectomy in seven consecutive pediatric patients.[33] The authors used the "allin-one" function of the LigaSure vessel sealing system (dissecting, coagulating, and cutting). For comparison, the data of seven consecutive patients who had undergone open retroperitoneal heminephroureterectomy were analyzed. The authors concluded that the feasibility of transperitoneal laparoscopic heminephroureterctomy (LH) using LigaSure was excellent. There were no intraoperative events or complications. However, the operative time for $\mathrm{LH}$ was higher $(144 \pm 18.4 \mathrm{~min}$.) compared to open heminephroureterectomy $(110 \pm 11.7 \mathrm{~min}$.), although the difference did not reach significance $(p=0.5)$. One randomized trial assessed the effectiveness and feasibility of the Ligasure system in a group of patients affected by renal-cell carcinoma and who underwent laparoscopic radical nephrectomy.[3] The authors concluded that the Ligasure vessel-sealing system seems to produce a consistent, reliable, permanent seal of vein, arteries, and tissue bundles by fusing the collagen in vessel walls and appears to be effective in advanced laparoscopic procedures. In one article, the authors reported of "meticulous hemostasis" using the 10-mm LigaSure devise for laparoscopic ureterolysis and omental wraping for the treatment of idiopathic retroperitoneal fibrosis in six patients.[34]

\section{Ex vivo experimental model}

A study by Kennedy at al. compared the LigaSure Vessel Sealing System with ultrasonic coagulation, bipolar coagulation, surgical clips and sutures.[35] In this study, 210 freshly excised porcine renal arteries ranging from $3-7 \mathrm{~mm}$ in diameter were occluded using the LigaSure VSD System, ultrasonic coagulator, bipolar forceps, mechanical clips or standard silk ties. The vessels were then cannulated and pressurized with saline using a syringe pump until the 
occlusion burst. Pressure was recorded when the occluded or normal vessel wall burst, or when the measurement system reached its maximum pressure of $900 \mathrm{mmHg}$. The study results demonstrated that the LigaSure VSD System creates seals that are stronger than other energybased ligation methods (ultrasonic coagulation and standard bipolar coagulation), and comparable in strength to mechanical ligation techniques such as clips and sutures.[36] Seals created by the LigaSure System were shown to withstand a minimum of three times normal systolic pressure.[29]

Lamberton et al. compared two bipolar sealing devices (LigaSure $\mathrm{V}$ and Gyrus PK), an ultrasonic device (Harmonic Scalpel ACE) and a novel device using nanotechnology (EnSeal PTC) in a large animal model to seal $5 \mathrm{~mm}$ bovine arteries.[37] The EnSeal PTC uses bipolar electrical energy but employs a nanotechnology feedback mechanism to reduce thermal spread by changing the energy required for sealing in response to tissue characteristics. The ultrasonic device demonstrated the least thermal spread, whereas the LigaSure V and Gyrus PK had the fastest sealing times (10.0 secs and $11.1 \mathrm{secs}$, respectively). The ultrasonic device was the slowest and had variable burst pressures. The highest burst pressure value was found with the LigaSure $V$ device $(385 \mathrm{mmHg})$. The lowest Tmax at $2 \mathrm{~mm}$ laterally was found with the Harmonic Scalpel $\left(49.9^{\circ} \mathrm{C}\right)$. In comparing the objective amount of particulates produced during vessel sealing the Harmonic Scalpel had the least amount of smoke produced while the Gyrus PK produced the greatest amount of smoke. All devices tested resulted in temperatures $2 \mathrm{~mm}$ away from tissue that were greater than 40 degrees $C$ and hence should be used with caution next to sensitive structures like the neurovascular bundle. However, potential limitations with this model include vessels without blood, an ex vivo experimental model and missing delayed failure.

\section{Radiofrequency ablation (RFA)}

The fundamental concept of RFA is transfer of alternating monopolar radiofrequency electrical current through needle electrodes into target tissue that results in ionic agitation, heating, and eventual desiccation with subsequent coagulative necrosis.[10] Radiofrequency energy can be applied using needles placed directly into tissues (dry RFA) or with ionic solutions perfused into tissues to act as a coupler (wet RFA).[38] Experimental and clinical experience, however, 
suggests that wet and dry RFA modalities are equally effective in causing cell death.[10] Different RFA instruments have already been used for laparoscopic partial nephrectomy and were proven to have good hemostatic potential.[39-40] Richstone et al. described the use of a novel bipolar radiofrequency (RF) system for the destruction of prostate tissue in an ex vivo model.[41] In their study, the bipolar RFA is capable of producing lesions with precise margins. Spread of heat was limited, evidenced histologically and by significant temperature drop off.

\section{Five-year view}

The increase in the number of day-case procedures performed and the rapid expansion of minimal access surgery have highlighted the importance of ensuring both meticulous surgical technique and haemostasis. The possibility of contaminated blood products and the hazards of blood transfusion are further stimuli for the avoidance of unnecessary blood transfusion. Therefore, urologists have to make the right choice to determine the optimal thermal coagulation method for each surgery.

\section{Endourology}

For the treatment of benign prostatic hyperplasia, transurethral monopolar resection of prostate (TURP) is the most effective surgical modality and gold standard.[42] However, transurethral resection (TUR) syndrome is an uncommon but potentially life-threatening complication of monopolar TURP in which glycine solution is used for irrigation.[43] Reich et al.'s prospective multicenter study on 10'654 BPH patients treated with TURP suggests a decrease in mortality $(0.1 \%)$ but morbidity, although reduced, continues to be high (11.1\%). B-TURP is preferable due to its more favourable profile, defined by the clinically relevant differences detected regarding complications such as TUR syndrome and clot retention. TURP using the TURis is a safe and efficacious treatment for $\mathrm{BPH}$ at 1 year with comparable resection time, mean weight of resected prostate tissue and lower morbidity. Also, bipolar TURP may prevent postoperative erectile dysfunction through limitation of tissue heating and extra prostatic current. In addition, withdrawal of acetylsalicylic acid (ASA), clopidogrel and anticoagulation prior to B-TURP is often 
not necessary allowing these devices to be used in the growing elderly population with cardiac stents. However, data on follow-up of $>12$ months are scarce for B-TURP, precluding long-term efficacy evaluation. A double-blind randomized trial that compares B-TURP with M-TURP for this complication is needed.

\section{Open surgery}

A wide variety of electrocoagulation devices have been used in open abdominal urologic surgery. However, some studies showed that the use of cautery devices in nerve sparing radical prostatectomy (nsRPE) is followed by a higher rate of erectile dysfunction.[44-45] On the other hand lower blood transfusion rates for nsRPE were reported when modern vessel sealing devices were used.[46] Modifications to reduce the adverse events of electrocoagulation may include sharp dissection in conjunction with bulldog clamps on the pedicles or release of neurovascular bundles without the use of electrocautery.[45] In addition, our findings suggested that the use of modern vessel-sealing devices for nerve-sparing radical prostatectomy is basically feasible and safe if a distance of $2.5 \mathrm{~mm}$ to the nerve is respected. Furthermore, we recommend protecting the nerve-vessel bundle by placing a clamp laterally to the device.[47] Bipolar cautery may not be safer than monopolar, which might be explained by the interaction of electric current with the biological tissue.[16] Also, lowering tissue temperature with irrigation was proven to be beneficial in reducing the collateral damage of the heat.[48] In tissues $>1 \mathrm{~cm}$ from cautery use, it has been shown that monopolar current causes a significantly higher temperature change compared with bipolar current but temperature elevation however are not sufficient to cause irreparable tissue damage with either current.[16] However, further studies are needed to fully investigate the pathologic damage associated with increase temperature due to electrocoagulation in the near future.

Recently, we investigated the lateral thermal spread and the corresponding injury caused by vessel sealing devices (LigaSure Impact ${ }^{\mathrm{TM}}$ and LigaSure $^{\mathrm{TM}} \mathrm{Axs}$ ) with regard to radical prostatectomies. To evaluate the precise lateral temperature spread along the musculofascial tissues, we used an infrared camera, continuous temperature measurement, and histology in an 
in vitro model. We demonstrated that both vessel-sealing devices have a significant thermal spread of $2.5 \mathrm{~mm}$ (Fig. 1).

LigaSure in open radical prostatectomy and open radical cystectomy are safe, and significantly decrease the blood loss, when compared to the conventional ligation method. However, daily clinical routine use of the disposable device causes considerable costs and has to be considered in the future. In this regard, the BiClamp® bipolar coagulation forceps as a reusable system seems to be a cost-effective and superior tool with regard to intraoperative blood loss, operating time and postoperative pain compared with conventional clamping and suture ligation.

\section{Laparoscopy}

The Ligasure vessel-sealing system seems to produce a consistent, reliable, permanent seal of veins, arteries, and tissue bundles by fusing the collagen in vessel walls. By reducing sutures and the number of instrument exchanges in the operating theatre, the Ligasure decreases operating time and blood loss. This new energy-based vessel-ligation device appears to be effective in advanced laparoscopic procedures. 


\section{Key issues}

- Inadequate haemostasis is one of the most important causes of morbidity and mortality following urological surgery

- Electrothermal devices are an effective tool to reduce blood loss and save time in surgery

- Despite the long term usage of coagulation in urology, there is an ongoing development of new devices

- For all urologic surgeries multiple electrothermal devices can be used safely, if the surgeon is aware of their limitations

- Well-designed multicentric randomized controlled trials (RCTs) with long-term follow-up and cost analysis are still needed to define the most suitable electrothermal device for each urologic procedure

- Bipolar transurethral resection (B-TUR) of the prostate (TURP) is preferable due to a more favourable safety profile (lower TUR syndrome)

- Data on follow-up of $>12$ months are scarce for B-TURP, precluding longterm efficacy evaluation

- Data on TUR in saline (TURis) are not yet mature to permit safe conclusions 


\section{References}

1. Massarweh NN, Cosgriff N, Slakey DP. Electrosurgery: history, principles, and current and future uses. J Am Coll Surg, 202(3), 520-530 (2006).

2. Issa MM. Technological advances in transurethral resection of the prostate: bipolar versus monopolar TURP. J Endourol, 22(8), 1587-1595 (2008).

3. Leonardo C, Guaglianone S, De Carli P, Pompeo V, Forastiere E, Gallucci M. Laparoscopic nephrectomy using Ligasure system: preliminary experience. $J$ Endourol, 19(8), 976-978 (2005).

4. Singh H, Desai MR, Shrivastav P, Vani K. Bipolar versus monopolar transurethral resection of prostate: randomized controlled study. J Endourol, 19(3), 333-338 (2005).

5. Ho HS, Yip SK, Lim KB, Fook S, Foo KT, Cheng CW. A prospective randomized study comparing monopolar and bipolar transurethral resection of prostate using transurethral resection in saline (TURIS) system. Eur Urol, 52(2), 517-522 (2007).

6. Fagerstrom T, Nyman CR, Hahn RG. Bipolar transurethral resection of the prostate causes less bleeding than the monopolar technique: a single-centre randomized trial of 202 patients. BJU Int, (2009).

7. Zubke W, Hornung R, Wasserer S et al. Bipolar coagulation with the BiClamp forceps versus conventional suture ligation: a multicenter randomized controlled trial in 175 vaginal hysterectomy patients. Arch Gynecol Obstet, 280(5), 753-760 (2009).

8. Cipolletta L, Bianco MA, Marmo R et al. Endoclips versus heater probe in preventing early recurrent bleeding from peptic ulcer: a prospective and randomized trial. Gastrointest Endosc, 53(2), 147-151 (2001).

9. Mamoulakis C, Ubbink DT, de la Rosette JJ. Bipolar versus Monopolar Transurethral Resection of the Prostate: A Systematic Review and Meta-analysis of Randomized Controlled Trials. Eur Urol, (2009).

10. Carraway WA, Raman JD, Cadeddu JA. Current status of renal radiofrequency ablation. Curr Opin Urol, 19(2), 143-147 (2009).

11. Mamoulakis C, Trompetter M, de la Rosette J. Bipolar transurethral resection of the prostate: the 'golden standard' reclaims its leading position. Curr Opin Urol, 19(1), 26-32 (2009).

12. Wang K, Advincula AP. "Current thoughts" in electrosurgery. Int J Gynaecol Obstet, 97(3), 245-250 (2007).

13. Kuntz RM. Laser treatment of benign prostatic hyperplasia. World J Urol, 25(3), 241-247 (2007).

14. Diamantis T, Kontos M, Arvelakis A et al. Comparison of monopolar electrocoagulation, bipolar electrocoagulation, Ultracision, and Ligasure. Surg Today, 36(10), 908-913 (2006).

15. Talic RF, El Tiraifi A, El Faqih SR, Hassan SH, Attassi RA, Abdel-Halim RE. Prospective randomized study of transurethral vaporization resection of the prostate using the thick loop and standard transurethral prostatectomy. Urology, 55(6), 886-890; discussion 890-881 (2000).

16. Mandhani A, Dorsey PJ, Jr., Ramanathan R et al. Real time monitoring of temperature changes in neurovascular bundles during robotic radical prostatectomy: thermal map for nerve-sparing radical prostatectomy. J Endourol, 22(10), 2313-2317 (2008). 
17. Alschibaja M, May F, Treiber U, Paul R, Hartung R. Recent improvements in transurethral high-frequency electrosurgery of the prostate. BJU Int, 97(2), 243-246 (2006).

18. Issa MM, Young MR, Bullock AR, Bouet R, Petros JA. Dilutional hyponatremia of TURP syndrome: a historical event in the 21st century. Urology, 64(2), 298-301 (2004).

19. Puppo P, Bertolotto F, Introini C, Germinale F, Timossi L, Naselli A. Bipolar transurethral resection in saline (TURis): outcome and complication rates after the first 1000 cases. J Endourol, 23(7), 1145-1149 (2009).

20. Ho H, Yip SK, Cheng CW, Foo KT. Bipolar transurethral resection of prostate in saline: preliminary report on clinical efficacy and safety at 1 year. $J$ Endourol, 20(4), 244-246; discussion 246-247 (2006).

21. Ko R, Tan AH, Chew BH, Rowe PE, Razvi H. Comparison of the thermal and histopathological effects of bipolar and monopolar electrosurgical resection of the prostate in a canine model. BJU Int, 105(9), 1314-1317 (2010).

22. Newcomb WL, Hope WW, Schmelzer TM et al. Comparison of blood vessel sealing among new electrosurgical and ultrasonic devices. Surg Endosc, 23(1), 90-96 (2009).

23. Daskalopoulos G, Karyotis I, Heretis I, Delakas D. Electrothermal bipolar coagulation for radical prostatectomies and cystectomies: a preliminary case-controlled study. Int Urol Nephrol, 36(2), 181-185 (2004).

24. Sengupta S, Webb DR. Use of a computer-controlled bipolar diathermy system in radical prostatectomies and other open urological surgery. ANZ J Surg, 71(9), 538-540 (2001).

25. Cook DJ, Guyatt GH, Salena BJ, Laine LA. Endoscopic therapy for acute nonvariceal upper gastrointestinal hemorrhage: a meta-analysis. Gastroenterology, 102(1), 139-148 (1992).

26. Kumar P, Fleischer DE. Thermal therapy for gastrointestinal bleeding. Gastrointest Endosc Clin N Am, 7(4), 593-609 (1997).

27. Zorn KC, Bhojani N, Gautam G et al. Application of ice cold irrigation during vascular pedicle control of robot-assisted radical prostatectomy: EnSeal instrument cooling to reduce collateral thermal tissue damage. J Endourol, 24(12), 1991-1996 (2010).

28. Gozen AS, Teber D, Rassweiler JJ. Principles and initial experience of a new device for dissection and hemostasis. Minim Invasive Ther Allied Technol, 16(1), 58-65 (2007).

29. Crawford ED KJ, Sieve V. Use of the LigaSure Vessel Sealing System in Urologic Cancer Surgery. Grand Round Urol, 1, 10-17 (1999).

30. Koyle MA, Oottamasathien S, Barqawi A, Rajimwale A, Furness PD, 3rd. Laparoscopic Palomo varicocele ligation in children and adolescents: results of 103 cases. J Urol, 172(4 Pt 2), 1749-1752; discussion 1752 (2004).

31. Hruby GW, Marruffo FC, Durak E et al. Evaluation of surgical energy devices for vessel sealing and peripheral energy spread in a porcine model. J Urol, 178(6), 2689-2693 (2007).

32. Richter S, Kollmar O, Neunhoeffer E, Schilling MK, Menger MD, Pistorius G. Differential response of arteries and veins to bipolar vessel sealing: evaluation of a novel reusable device. J Laparoendosc Adv Surg Tech A, 16(2), 149-155 (2006).

33. Metzelder ML, Kubler JF, Nustede R, Ure BM. LigaSure in laparoscopic transperitoneal heminephroureterectomy in children: a comparative study. J Laparoendosc Adv Surg Tech A, 16(5), 522-525 (2006).

34. Simone G, Leonardo C, Papalia R, Guaglianone S, Gallucci M. Laparoscopic ureterolysis and omental wrapping. Urology, 72(4), 853-858 (2008). 
35. Kennedy JS, Stranahan PL, Taylor KD, Chandler JG. High-burst-strength, feedbackcontrolled bipolar vessel sealing. Surg Endosc, 12(6), 876-878 (1998).

36. Kennedy J TK, Chandler J. High burst strength, servoregulated, bipolar vessel sealing. Paper presented at: 5th Annual Congress of The European Association for Endoscopic Surgery; Istanbul, Turkey; Joint Euro-Asian Congress of Endoscopic Surgery, Bologna, Italy. ( June 1997).

37. Lamberton GR, Hsi RS, Jin DH, Lindler TU, Jellison FC, Baldwin DD. Prospective comparison of four laparoscopic vessel ligation devices. J Endourol, 22(10), 2307-2312 (2008).

38. Patel VR, Leveillee RJ, Hoey MF, Herron AJ, Zaias J, Hulbert JC. Radiofrequency ablation of rabbit kidney using liquid electrode: acute and chronic observations. $J$ Endourol, 14(2), 155-159 (2000).

39. Haghighi KS, Steinke K, Hazratwala K, Kam PC, Daniel S, Morris DL. Controlled study of Inline radiofrequency coagulation-assisted partial nephrectomy in sheep. J Surg Res, 133(2), 215-218 (2006).

40. Pareek G, Wilkinson ER, Schutt D et al. Haemostatic partial nephrectomy using bipolar radiofrequency ablation. BJU Int, 96(7), 1101-1104 (2005).

41. Richstone L, Ziegelbaum M, Okeke $\mathrm{Z}$ et al. Ablation of bull prostate using novel bipolar radiofrequency ablation probe. J Endourol, 23(1), 11-16 (2009).

42. Crowley AR, Horowitz M, Chan E, Macchia RJ. Transurethral resection of the prostate versus open prostatectomy: long-term mortality comparison. J Urol, 153(3 Pt 1), 695-697 (1995).

43. Mebust WK, Holtgrewe HL, Cockett AT, Peters PC. Transurethral prostatectomy: immediate and postoperative complications. A cooperative study of 13 participating institutions evaluating 3,885 patients. J Urol, 141(2), 243-247 (1989).

44. Ahlering TE, Eichel L, Chou D, Skarecky DW. Feasibility study for robotic radical prostatectomy cautery-free neurovascular bundle preservation. Urology, 65(5), 994-997 (2005).

45. Ahlering TE, Skarecky D, Borin J. Impact of cautery versus cautery-free preservation of neurovascular bundles on early return of potency. $J$ Endourol, 20(8), 586-589 (2006).

46. Gelabert Mas A, Bielsa Gali O. [Saving surgical time with great hemostatic safety and efficiency using the LIGA-SURE system in complete pelvic urologic surgery]. Arch Esp Urol, 55(7), 839-841 (2002).

47. Eberli D, Hefermehl LJ, Sulser T, Knonagel H. LATERAL TEMPERATURE SPREAD OF VESSEL-SEALING DEVICES: ARE THEY SAFE FOR NERVE SPARING RADICAL PROSTATECTOMY? Eur. Urol. Suppl., 8(4), 222-222 (2009).

48. Lepor H, Gregerman M, Crosby R, Mostofi FK, Walsh PC. Precise localization of the autonomic nerves from the pelvic plexus to the corpora cavernosa: a detailed anatomical study of the adult male pelvis. J Urol, 133(2), 207-212 (1985).

49. Landman J, Kerbl K, Rehman J et al. Evaluation of a vessel sealing system, bipolar electrosurgery, harmonic scalpel, titanium clips, endoscopic gastrointestinal anastomosis vascular staples and sutures for arterial and venous ligation in a porcine model. $J$ Urol, 169(2), 697-700 (2003).

50. Smaldone MC, Gibbons EP, Jackman SV. Laparoscopic nephrectomy using the EnSeal Tissue Sealing and Hemostasis System: successful therapeutic application of nanotechnology. JSLS, 12(2), 213-216 (2008). 
51. Urena R, Mendez F, Woods M, Thomas R, Davis R. Laparoscopic partial nephrectomy of solid renal masses without hilar clamping using a monopolar radio frequency device. $J$ Urol, 171(3), 1054-1056 (2004).

52. Phillips JM, Narula N, Deane LA et al. Histological evaluation of cold versus hot cutting: clinical impact on margin status for laparoscopic partial nephrectomy. J Urol, 180(6), 2348-2352 (2008).

53. Ilbeigi P, Ahmed M, Szobota J, Munver R, Sawczuk IS. Open partial nephrectomy using saline-enhanced monopolar radiofrequency device: evaluation of novel surgical technique with TissueLink DS3.0 Dissecting Sealer. Urology, 65(3), 578-582 (2005).

\section{Acknowledgement statement}

We would like to thank Damina Balmer, M.Sc., for her editorial assistance.

\section{Financial disclosure}

None 


\section{Figure 1 - Lateral thermal spread in vitro}
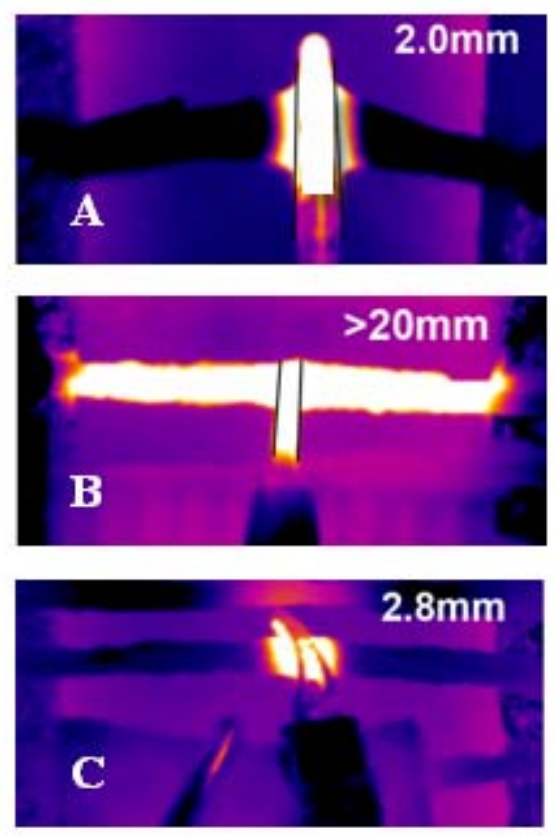

This figure shows the effect of different electrothermal modalities on the temperature of adjacent tissues in vitro. A) Vessel Sealing Device (LigaSure LS1500C, at completion of sealing process), B) Monopolar (Hot Shears, 60W 2 Sec) and C) Bipolar (Maryland Forceps, 60W $2 \mathrm{Sec}$ ). Temperature above $45^{\circ} \mathrm{C}$ are displayed in white. 
Tables

Table 1 - Overview of the different electrothermal sealing systems in human clinical studies

\begin{tabular}{|c|c|c|c|c|c|c|}
\hline $\begin{array}{l}\text { Reference } \\
\text { Sengupta et al.[24] }\end{array}$ & $\begin{array}{l}\mathrm{n} \\
32\end{array}$ & $\begin{array}{l}\text { Electrothermal sealing system } \\
\text { Liganure in open urological procedures vs. } \\
\text { contro roup }\end{array}$ & $\begin{array}{l}\text { Blood loss } \\
\text { Significant lower }\end{array}$ & $\begin{array}{l}\text { Operative time } \\
\text { Significant shorter }\end{array}$ & Thermal spread & $\begin{array}{l}\text { Notes } \\
\text { Small sample size } \\
\text { No randomization }\end{array}$ \\
\hline Daskalopoulos et al.[23] & 58 & $\begin{array}{l}\text { LigaSure in open prostatectomy and cystectomy } \\
\text { vs. conventional ligation }\end{array}$ & Significant lower & Significant shorter & & $\begin{array}{l}\text { Small sample size } \\
\text { No randomization }\end{array}$ \\
\hline Mamoulakis et al.[9] & meta analysis & B-TURP vs. M-TURP & no difference & no difference & & $\begin{array}{l}\text { limited follow-up (<yyear), } \\
\text { low trial quality }\end{array}$ \\
\hline Leonardo et al.[3] & 30 & $\begin{array}{l}\text { LigaSure Atlas in laparoscopic nephrectomy } \\
\text { vs. monopolar electrocautery and shears and } \\
\text { standard clips }\end{array}$ & Significant lower & Significant shorter & & Small sample size \\
\hline Ho et al.[5] & 100 & M-TURP vs. TURIS & no difference & no difference & & $\begin{array}{l}\text { larger follow-up and larger number } \\
\text { of patients are needed }\end{array}$ \\
\hline Issa e tal.:499] & 1802 & M-TURP vs. PK B-TURP & no difference & no difference & & lower complication rate with TURIS \\
\hline Simone et al.[34] & 6 & 10-mm LigaSure atlas in laparoscopic ureterolysis & meticulous hemostasis & time saving & & $\begin{array}{l}\text { Midterm results } \\
\text { Small sample size }\end{array}$ \\
\hline Smaldone et al.[50] & case report & $\begin{array}{l}\text { EnSeal Tissue Sealing and Hemostasis System } \\
\text { In laparoscopic nephrectomy }\end{array}$ & blood loss was minimal & & & Caser report \\
\hline Urena et al.[51] & 10 & $\begin{array}{l}\text { Monopolar radio frequency device (Tissuelink DS } \\
\text { dissecting sealer) in I laparoscopici partial nephrectomy } \\
\text { without clamping the renal vasculature }\end{array}$ & $\begin{array}{l}\text { provides adequate hemostasis } \\
\text { iy }\end{array}$ & & Scant tissue charring & $\begin{array}{l}\text { Retrospective study } \\
\text { Small sample size }\end{array}$ \\
\hline Phililips et al.[52] & 40 & $\begin{array}{l}5 \mathrm{~mm} \text { LigaSure vs. Harmonic Scalpel vs. cold excision } \\
\text { in NSS }\end{array}$ & & & No effect on soff tissue margin & $\begin{array}{l}\text { Increased artifact using } \\
\text { ultrasonic shears } \\
\text { Higher positive margin rate } \\
\text { without vessel clamping }\end{array}$ \\
\hline Metzelder et a l. $^{37}$ & 7 & $\begin{array}{l}\text { Ligasure in laparoscopoic transsperitoneal } \\
\text { Heminephrourteterectomy in children }\end{array}$ & no intraoperative complications & $\begin{array}{l}\text { Mean operative time } \\
\text { longer than open } \\
\text { heminphroureterectomy }\end{array}$ & & $\begin{array}{l}\text { Small sample size } \\
\text { No RCT }\end{array}$ \\
\hline $\begin{array}{l}\text { Mamoulakis et al[.9] } \\
\text { Ilbeigi ta tal[53] }\end{array}$ & 1406 & $\begin{array}{l}\text { Bipolala vs. Monopolar TURP } \\
\text { Tissuelinke device (radiofrequency energy } \\
\text { counled }\end{array}$ & $\begin{array}{l}\text { No difference in transtusion rate } \\
\text { Significant lower }\end{array}$ & $\begin{array}{l}\text { No meta-analysis could b } \\
\text { No significance }\end{array}$ & $\begin{array}{l}\text { e performed } \\
\text { Charring up to } 2 \mathrm{~mm}\end{array}$ & Small sample size \\
\hline
\end{tabular}

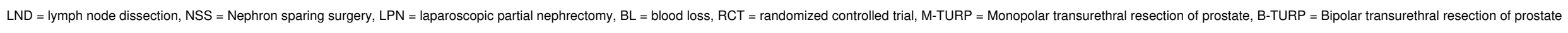


Table 2 - Overview of the different devices

\begin{tabular}{|c|c|c|c|c|}
\hline $\begin{array}{l}\text { Device } \\
\text { Ligasure }\end{array}$ & $\begin{array}{l}\text { Primary usage } \\
\text { Arteries \& veins }<7 \mathrm{~mm}\end{array}$ & $\begin{array}{l}\text { Sate at what distance to nerves } \\
\text { Tmax. at } 2 \mathrm{~mm} \text { lateraly } 55.5^{\circ} \mathrm{C}\end{array}$ & $\begin{array}{l}\text { weakness } \\
\text { capillaries }\end{array}$ & $\begin{array}{l}\text { best use } \\
\text { radical prostatectomy, nephrectomy and cystectomy, } \\
\text { arteries and veins }<7 m m\end{array}$ \\
\hline Gyrus Plasmakinetic bipolar device & $\begin{array}{l}\text { Laparoscopic nephrectomy } \\
\text { Arteres } \leq 5 m m \text {. }\end{array}$ & $\begin{array}{l}\text { Thermal spread } 3.5 \mathrm{~mm} \\
\end{array}$ & low burst pressure $(204 \mathrm{Ha})$ & \\
\hline Tissulunke device & $\begin{array}{l}\text { Arrenes } s 5 \mathrm{~mm} \\
\text { Arteries }<3 \mathrm{~mm}\end{array}$ & $\begin{array}{l}\text { Tmaxa a a } 2 m \text { mm laterally } 49.9^{\circ} \\
\text { Charring up po }\end{array}$ & (1) & \\
\hline EnSeal PTC & Atreries < < $5 \mathrm{~mm}$ & Tmax. at $2 \mathrm{~mm}$ laterally $55.5^{\circ}$ & lo burst pressure (255Hg) & \\
\hline KTP laser & TUR-P, LPN & no clean resection margins & & BPO \\
\hline $\begin{array}{l}\text { Habib Sealer } \\
\text { SonoSurg }\end{array}$ & LPN & no cleaa resection margins & higher BL & \\
\hline Monopolar TUR-P & TUR-P & & TUR syndrome & BPO \\
\hline $\begin{array}{l}\text { Bipolar TUR-P } \\
\text { TURis }\end{array}$ & $\begin{array}{l}\text { TUR-P } \\
\text { TUR-P }\end{array}$ & & & $\begin{array}{l}\text { BPO. Minimized bleeding risk in patients on aspirin/clopiddogrel } \\
\text { BPO. Combines the advantages of vaporisation with the }\end{array}$ \\
\hline Biclamp® bipolar coagulation forceps & Ligate 2.7mm arteries and veins & & thermal spread increased in veins & $\begin{array}{l}\text { Benefits of bipolar resection } \\
\text { LLagte 2.7mm atreres and veins }\end{array}$ \\
\hline & 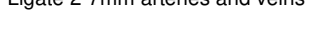 & & extra to 3 seconds needed to seal arteries and ve & \\
\hline
\end{tabular}

BL = blood loss, LPN = Laparoscopic partial nephrectomy, BPO = benign prostatic obstruction, TURis = transurethral resection in saline, RTTA = radiofrequency yinterstitial tumor ablation 